\title{
Psychosocial Moderators of Perceived Stress, Anxiety and Depression in University Students: An International Study
} \author{
Barbara C. Y. Lo ${ }^{4}$ \\ ${ }^{1} \mathrm{PhD}$ (Clin) Bond University, Gold Coast, Australia \\ ${ }^{2}$ Bond University, Gold Coast, Australia \\ ${ }^{3}$ ARNP, University of Florida, Gainesville, USA \\ ${ }^{4} \mathrm{PhD}$ University of Hong Kong, Hong Kong, China \\ Email: stephy.mcgrath87@gmail.com
}

Aileen M. Pidgeon', Stephanie McGrath'2, Heidi B. Magya3, Peta Stapleton',

Received September 2014

\begin{abstract}
Extensive research shows university students experience high levels of stress, which can lead to the development of mental health problems such as anxiety and depression. Preliminary evidence supports the role of psychosocial factors such as perceived social support (PSS) and campus connectedness (CC) as protective factors in the development of mental health problems in university students. However, research conducted on the potential ameliorating effects of social support on stress applying Cohen and Wills' (1985) stress-buffering hypothesis produced weak, inconsistent, and even contradictory results. In addition, little attention has been given to examining the protective role of $\mathrm{CC}$ in the relationships between perceived stress, anxiety, and depression. The current study examined the applicability of CC and PSS in buffering the relationships been perceived stress, anxiety, and depression across an international sample comprised of university students $(N$ = 206) from Australia, Hong Kong, and the United States. The prediction that CC and PSS would moderate the relationships between perceived stress, anxiety, and depression was partially supported. The results indicated CC moderated the relationship between perceived stress and depression but did not moderate the relationship between perceived stress and anxiety. PSS did not moderate the relationship between perceived stress and depression or the relationship between perceived stress and anxiety, thus rejecting the stress-buffering hypothesis. These findings suggest less emphasis should be placed on PSS as a protective factor, with universities focusing on enhancing CC to reduce the high prevalence of mental health problems to promote psychological wellbeing among students.
\end{abstract}

\section{Keywords}

Perceived Stress, Anxiety, Depression, Psychosocial, Perceived Social Support, Campus Connectedness, Stress-Buffering Hypothesis, Moderating, Buffering 


\section{Introduction}

The transition into higher education is a stressful time as university students face multiple stressors such as academic overload, constant pressure to succeed, competition with peers, and in some countries financial burden as well as concerns about future career prospects [1]. While many university students adjust effectively to the university context, a large proportion of students are adversely impacted by stress and are at risk of developing mental health problems [2].

The prevalence of mental health issues in university students is of universal concern, with international studies revealing clinical levels of psychopathology, including anxiety and depression in student populations globally [2]-[5]. Thus, the mental health of university students has been the subject of increasing focus in recent years with evidence demonstrating that university students experience higher levels of psychological distress, including anxiety and depression, in comparison to non-student populations [2] [6]. Moreover, research has shown approximately $40 \%$ of university students with diagnosable mental health conditions do not seek clinical services or access university support services [7].

Research suggests psychosocial factors such as perceived social support and campus connectedness may play a protective role in the adverse consequences of perceived stress among university students. Perceived social support has been shown to be positively associated with psychological wellbeing [8]-[10]. While campus connectedness is a relatively new construct defined as a form of social connectedness and belonging that is specific to the university context and is also positively associated with psychological wellbeing and adjustment in university students [11]. Considering many university students are not seeking professional assistance for psychological issues, an investigation into the protective role that key psychosocial factors play in promoting psychological wellbeing and protecting university students from the development of mental health problems is warranted. The current study will examine the protective role of campus connectedness and perceived social support on the relationships between perceived stress, anxiety, and depression among university students.

\subsection{Perceived Stress, Anxiety, and Depression}

While the literature suggests various risk factors are associated with the development of anxiety and depression, the positive association between perceived stress, anxiety, and depression has been demonstrated in numerous studies [12] [13]. High levels of perceived stress increases the risk for an individual to develop anxiety and depression. However, university students worldwide are shown to be a high risk group with prevalence rates being higher than the general population [14]. Stallman [15] found a significantly higher prevalence of mental health problems in Australian university students than the general population with $83.9 \%$ of students reporting heightened levels of psychological distress including stress, anxiety, and depression. Eisenberg, Hunt, and Speer [16] assessed students across 26 United States universities and found 17.3\% met the criteria for depression, $7.8 \%$ generalised anxiety disorder, $4.1 \%$ panic disorder, and a total of $6.3 \%$ reported suicidal ideation. A study conducted by Wong, Cheung, Chan, Ma, and Tang [17] in a sample of university students across 10 universities in Hong Kong revealed a prevalence of anxiety, depression, and stress with $21 \%$ of students experiencing moderate depression, 41\% moderate anxiety, and 27\% moderate stress. This research highlights the importance of developing an understanding of the psychosocial factors that protect students against the adverse effects of perceived stress.

\subsection{Perceived Social Support}

Perceived social support has been consistently shown to be positively associated with psychological wellbeing [8]-[10]. Perceived social support is defined as an individual's potential access to social support resources, that is, an individual's belief that support is available if needed [18]. Perceived social support has been repeatedly linked to positive psychological and health outcomes [18]. The breadth of research on perceived social support has led researchers to examine its role in moderating the effects of perceived stress on anxiety and depression [8] [19] [20]. A moderator is a variable that alters the strength of the relationship between a predictor variable and an outcome variable [21].

The stress-buffering hypothesis developed by Cohen and Wills [22] suggests perceived social support ameliorates the adverse effects of stressful situations. Cohen and Wills' hypothesis links with Lazarus and Folkman's [23] transactional theory of stress in that perceptions of social support may lead an individual to appraise a 
threatening situation as less stressful. Cohen and Wills proposed that perceived social support acts as a protective psychosocial factor for individuals experiencing high levels of perceived stress. As such, perceived social support is thought to reduce the adverse effects of perceived stress through the belief that an individual can access coping resources such as social support if needed [8]. Perceived social support may decrease the experience of stress by providing a reappraisal of the stressor, thereby reducing the affective, physiological, and cognitive reactions that make up the experience of stress [24]. Since Cohen and Wills' proposal of the stress-buffering hypothesis, many researchers have tested this process, however the literature contains inconsistent findings. Some studies have demonstrated support for a buffering model of perceived social support consistent with the stress-buffering hypothesis [25] while others have only found support for a main effect model of perceived social support [26].

\subsection{Campus Connectedness}

In comparison to perceived social support, social connectedness is a global construct that encompasses much more than just perceived interpersonal relations [27]. According to Lee and Robbins [28] social connectedness is a person's subjective awareness of closeness with their social world. Social connectedness has been found to be negatively associated with perceived stress, anxiety, and depression [29] [30]. Therefore, connectedness within a university context is an important psychosocial variable to examine, as many university students experience maladjustment issues in adapting to a new social environment upon transitioning into university [31]. Campus connectedness refers to social connectedness within the university context and has been defined by Lee and Robbins [28] as a student's sense of psychological belonging in a university environment. Research demonstrates that a lack of connectedness in university students has a negative impact on adjustment and psychological functioning. University students who report low connectedness also report fewer meaningful and supportive relationships with others [31]. Furthermore, university students with low levels of connectedness report higher levels of psychological distress due to their lack of meaningful connections with others [27]. Research has also demonstrated social connectedness is inversely related to perceived stress, anxiety, and depression in university students [28]-[30]. This research suggests that university students with higher levels of connectedness have lower levels of perceived stress, anxiety, and depression. Additionally, Furthermore, Rude and Burham [32] proposed connectedness should be investigated as a protective factor against depression. It is therefore essential that students feel connected on campus to ensure they adjust to university life and maintain their psychological wellbeing throughout their studies.

Although campus connectedness has been found to be negatively associated with perceived stress, anxiety, and depression, its moderating effect on these relationships is yet to be investigated. A paucity of research exists in examining the protective role of additional psychosocial characteristics such as campus connectedness, in moderating (buffering) the relationships between perceived stress, anxiety, and depression in university students. Further research is required to investigate the dynamic interplay among these variables. The current study will address the gap in the literature by evaluating the applicability of campus connectedness in buffering the relationship between perceived stress, anxiety, and depression.

\subsection{The Current Study}

The purpose of the current study was to examine psychosocial moderators of perceived stress, anxiety, and depression in an international sample of university students. The study also aimed to evaluate Cohen and Wills' [22] stress-buffering hypothesis of perceived social support, in addition to investigating the role of campus connectedness as a moderator in the relationships between perceived stress, anxiety, and depression. A series of four moderations were planned to investigate the following hypotheses:

H1. Perceived social support moderates the relationship between perceived stress and depression. Higher levels of perceived social support would buffer the effects of perceived stress on depression.

H2. Campus connectedness moderates the relationship between perceived stress and depression. Higher levels of campus connectedness would buffer the effects of perceived stress on depression.

H3. Perceived social support moderates the relationship between perceived stress and anxiety. Higher levels of perceived social support would buffer the effects of perceived stress on anxiety.

H4. Campus connectedness moderates the relationship between perceived stress and anxiety. Higher levels of campus connectedness would buffer the effects of perceived stress on anxiety. 


\section{Method}

\subsection{Participants}

Participants for the current study consisted of 206 university students aged between 18 to 59 years $(M=22.08$, $S D=5.57)$ including 160 (77.7\%) females and 46 (22.3\%) males. The sample included university students from Bond University, Australia, The University of Hong Kong, and The University of Florida. Inclusion criteria required participants to be aged 18 years and over.

\subsection{Measures}

Perceived Stress Scale (PSS). The PSS [33] is a 10-item scale designed to measure perceptions of stress. Four positively stated items require reverse scoring. To calculate a global measure of percieved stress the total number of items on the scale are summed with higher scores indicating higher levels of percieved stress.

The Depression Scale and Anxiety Scale (DASS-21). The current study used the Depression Scale and Anxiety Scale from the DASS-21, a short form version of the DASS-42 [34]. Scores for each scale are calculated through the summation of items. As the DASS-21 is a shortened version of the full DASS-42, the scores for each of the scales are to be multiplied by two. Higher scores on each scale are indicative of higher scores of depression or anxiety.

Campus Connectedness Scale (CCS). The CCS is a 14-item self report scale designed to measure university student's perception of belongingness on the university campus [28]. Eight negatively worded items require reverse scoring. The 14-items are summed with higher scores indicative of higher levels of campus connectedness.

Multidimensional Scale of Perceived Social Support (MSPSS). The MSPSS is a 12-item self-report scale designed to measure how individuals perceive their global social support system across three sources: family, friends, and significant other [9]. A global measure of perceived social support is obtained by summing the responses on the 12-items with higher values indicating higher levels of perceived social support.

\section{Results}

Separate moderated multiple regression analyses were conducted to determine if each of the moderators interacted to buffer the effects of perceived stress on the outcome variables of anxiety and depression. Moderation effects are assessed through the creation of a statistical interaction term comprised of the predictor variable multiplied by the moderator variable. Chaplin [35] conducted a comprehensive review of the literature and found that interaction term effect sizes generally account for between $1 \%$ and $3 \%$ of the variance in the outcome variable. Additionally, Evans [36] states moderation effects are so difficult to detect that even interaction terms accounting for $1 \%$ of the variance should be considered important. To reduce potentially problematic family wise inflation the four moderations were conducted within two separate regression models [37]. The first model investigated whether campus connectedness or perceived social support moderated the relationship between perceived stress and depression. The second model investigated whether campus connectedness or perceived social support moderated the relationship between perceived stress and anxiety. In each model, university was entered at Step 1 as a covariate to control for differences between universities on the outcome variables. At Step 2 the centered predictor and moderators were entered simultaneously, at Step 3 the interaction of the first moderator and predictor were entered, and at Step 4 the interaction of the second moderator and predictor were entered.

Model 1. At Step 1 of the analysis, university was added to the regression equation and the overall model was significant, $F(1,194)=7.59, p=0.006$. University explained a significant $4 \%$ of the variance in depression scores. Thus, university was significantly predictive of depression scores, $\beta=.19, p=0.006$, such that university students from Hong Kong had higher depression scores than university students from Australia and the United States. At Step 2, after controlling for the effects of university, perceived stress, perceived social support, and campus connectedness were added to the regression equation and the overall model was significant, $F(4,191)=$ 42.74, $p<0.001$. Perceived stress, perceived social support, and campus connectedness accounted for 44\% of the variance in depression, $\Delta F(3,191)=52.44, p<0.001$. At this step, perceived stress was a significant positive predictor of depression, $\beta=0.55, p<0.001$, indicating that a $1 S D$ increase in perceived stress resulted in a $0.55 S D$ increase in depression. Perceived social support at this step was a non-significant predictor of depression, $\beta=-0.10, p=0.124$. Campus connectedness at this step was a significant negative predictor of depression, $\beta=-0.15 \mathrm{p}=0.031$, indicating that a $1 S D$ increase in campus connectedness results in a $0.15 S D$ decrease in 
depression. At Step 3 of the analysis, the perceived stress ${ }^{x}$ campus connectedness interaction term was added to the regression equation and the overall model was significant, $F(5,190)=36.33, p<0.001$. Consistent with hypotheses, the perceived stress ${ }^{X}$ campus connectedness interaction term was significantly predictive of depression, explaining an additional $2 \%$ of the variance in scores on depression, $\Delta F(1,190)=6.13, p=0.01$. Therefore, the predictive relationship between perceived stress and depression varied according to campus connectedness. At Step 4, the perceived stress ${ }^{X}$ perceived social support interaction term was added to the regression equation and the overall model was significant, $F(6,189)=30.30, p<0.001$. Inconsistent with hypotheses, the perceived stress ${ }^{\mathrm{X}}$ perceived social support interaction term was non-significantly predictive of depression, explaining no further variance in scores on depression, $\Delta F(1,189)=0.56, p=0.457$. Therefore the predictive relationship between perceived stress and depression did not vary according to perceived social support (Table 1).

To follow up the significant interaction effect of perceived stress ${ }^{x}$ campus connectedness Dawson's [38] simple slope analyses were conducted to assess the nature of the interaction through a comparison of high campus connectedness scores $(+1 S D)$ with low campus connectedness scores $(-1 S D)$. The findings revealed, when campus connectedness was low, perceived stress was significantly predictive of depression, $\beta=0.68, p<0.001$. At high levels of campus connectedness, perceived stress was significantly predictive of depression, $\beta=0.45, p$ $<0.001$. As such, the nature of the interaction appeared to be that campus connectedness at high levels had a buffering effect on the relationship between perceived stress and depression as represented by the decrease in the strength of the positive slope. Therefore, an increase in levels of campus connectedness results in a decrease in the magnitude of the effect of perceived stress on depression. A graphical representation of the interaction is displayed in Figure 1.

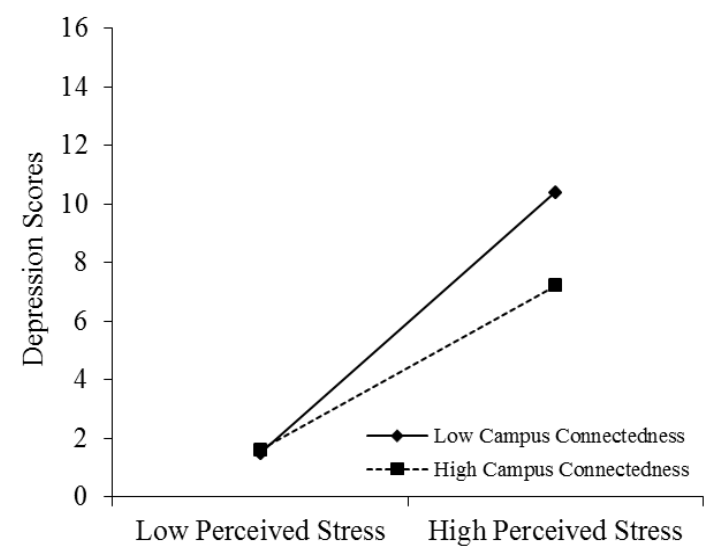

Figure 1. Campus connectedness moderated the relationship between perceived stress and depression.

Table 1. Model 1 investigating campus connectedness and perceived social support as moderating the relationships between perceived stress and depression.

\begin{tabular}{ccccc}
\hline & $\beta$ & $B$ & SE $B$ & $95 \%$ CI for $B$ \\
\hline Constant & & 4.14 & 1.10 & {$[1.97,6.30]$} \\
University & 0.19 & $1.55^{* * *}$ & 0.56 & {$[0.44,2.65]$} \\
Constant & & 5.67 & 0.83 & {$[4.02,7.30]$} \\
Perceived stress & 0.55 & $0.54^{* * *}$ & 0.06 & {$[0.43,0.66]$} \\
Perceived social support & -0.10 & -0.06 & 0.04 & {$[-0.13,0.02]$} \\
Campus connectedness & -0.07 & $-0.07^{*}$ & 0.03 & {$[-0.13,-0.02]$} \\
Constant & & 5.19 & 0.84 & {$[3.53,6.88]$} \\
Perceived stress ${ }^{\mathrm{X}}$ Campus connectedness & -0.13 & $-0.01^{* *}$ & 0.00 & {$[-0.12,-0.00]$} \\
Constant & & 10.71 & 7.45 & {$[-3.99,25.41]$} \\
Perceived stress ${ }^{\mathrm{X}}$ Perceived social support & -0.30 & -0.00 & 0.01 & {$[-0.02,0.02]$} \\
\hline
\end{tabular}

Note: $N=$ number of participants. $C I=$ confidence intervals. ${ }^{*} p<0.05, \stackrel{* *}{p} p<0.01,{ }^{* * *} p<0.001$. 
Model 2. At Step 1 of the analysis, university was added to the regression equation and the overall model was non-significant, $F(1,194)=1.81, p=0.180$. University explained a non-significant $1 \%$ of the variance in anxiety scores. Thus, university was non-significantly predictive of anxiety scores. At Step 2, after controlling for the effects of university, perceived stress, perceived social support, and campus connectedness were added to the regression equation and the overall model was significant, $F(4,191)=25.37, p<0.001$. Perceived stress, perceived social support, and campus connectedness accounted for $34 \%$ of the variance in anxiety scores, $\Delta F$ ( 3 , $191)=32.93, p<0.001$. At this step, perceived stress was a significant predictor of anxiety, $\beta=0.44 p<0.001$, indicating that a $1 S D$ increase in perceived stress resulted in a $0.44 S D$ increase in anxiety. Perceived social support at this step was a non-significant predictor of anxiety, $\beta=0.13, p=0.063$. Campus connectedness at this step was a significant negative predictor of anxiety, $\beta=-0.30, p<0.001$, indicating that a $1 S D$ increase in campus connectedness resulted in a 0.13 decrease in anxiety. At Step 3 of the analysis, the perceived stress $x$ campus connectedness interaction term was added to the regression equation and the overall model was significant, $F(5,190)=20.39, p<0.001$. Inconsistent with hypothesis, the perceived stress ${ }^{\mathrm{X}}$ campus connectedness interaction term Therefore, the predictive relationship between perceived stress and anxiety did not vary according to campus connectedness. At Step 4, the perceived stress $\mathrm{x}$ perceived social support interaction term was added to the regression equation and the overall model was significant, $F(6,189)=17.39, p<0.001$. Inconsistent with hypotheses, the perceived stress ${ }^{\mathrm{x}}$ perceived social support interaction term was non-significantly predictive of anxiety, explaining no further variance in scores on anxiety, $\Delta F(1,189)=1.92, p=0.168$. Therefore the predictive relationship between perceived stress and anxiety did not vary according to perceived social support (Table 2).

\section{Discussion}

The aim of the current study was to examine psychosocial moderators of the relationships between perceived stress, anxiety, and depression in an international level in a sample of university students. It was firstly predicted that perceived social support would moderate the relationship between perceived stress and depression. Specifically, perceived social support would buffer the effects of perceived stress on depression, thereby reducing the strength of the relationship. The results of the moderation analysis did not support hypothesis two, as perceived social support did not moderate the relationship between perceived stress and depression. These findings do not support Cohen and Wills' [22] stress-buffering hypothesis. These results demonstrate perceived social support does not interact with perceived stress to protect university students from depression thus rejecting a buffering model of perceived social support.

Hypothesis two, evaluated the role of campus connectedness as a moderator in the relationship between perceived stress and depression. It was hypothesised that campus connectedness would buffer the relationship between perceived stress and depression, such that higher levels of campus connectedness would decrease the

Table 2. Model 2 investigating campus connectedness and perceived social support as moderating the relationships between perceived stress and anxiety.

\begin{tabular}{ccccc}
\hline & $\beta$ & $B$ & SE $B$ & $95 \%$ CI for $B$ \\
\hline Constant & & 5.42 & 1.07 & {$[3.31,7.54]$} \\
University & 0.10 & 0.74 & 0.55 & {$[-0.34,1.82]$} \\
Constant & & 6.50 & 0.89 & {$[4.75,8.25]$} \\
Perceived stress & 0.44 & $0.42^{* * *}$ & 0.06 & {$[0.23,0.54]$} \\
Perceived social support & 0.13 & 0.07 & 0.04 & {$[-0.00,0.15]$} \\
Campus connectedness & -0.30 & $-0.14^{* * *}$ & 0.03 & {$[-0.20,-0.70]$} \\
Constant & & 6.33 & 0.91 & {$[4.53,8.13]$} \\
Perceived stress ${ }^{\mathrm{X}}$ Campus connectedness & -0.05 & -0.00 & 0.00 & {$[-0.01,0.01]$} \\
Constant & & -4.77 & 8.06 & {$[-20.68,11.14]$} \\
Perceived stress ${ }^{\mathrm{X}}$ Perceived social support & 0.62 & 0.01 & 0.01 & {$[-0.02,0.01]$} \\
\hline
\end{tabular}

Note: $N=$ number of participants. $C I=$ confidence intervals. ${ }^{*} p<0.05,{ }^{* *} p<0.01,{ }^{* * *} p<0.001$. 
strength of the positive association between perceived stress and depression. The results of the moderation analyses supported this hypothesis. A significant interaction of campus connectedness and perceived stress in predicting depression was found, with the interaction term accounting for $2 \%$ of the variance in depression scores. Again, this result is consistent with Chaplin's [35] review of the literature, in which interaction terms generally account for between $1 \%$ to $3 \%$ of the variance. The nature of this interaction appeared to be that campus connectedness at high levels buffered the relationship between perceived stress and depression, that is, campus connectedness reduced the strength of the association between the two variables. However, at low levels of campus connectedness the positive relationship between perceived stress and depression increased. These results demonstrate campus connectedness interacts with perceived stress to protect university students from depression.

Hypothesis three, in accordance with Cohen and Wills' [22] stress-buffering hypothesis examined whether perceived social support moderated the relationship between perceived stress and anxiety. It was predicted perceived social support would buffer the relationship between perceived stress and anxiety. This hypothesis was not supported, as the interaction term of perceived social support and perceived stress in predicting anxiety was non-significant. These findings do not support the stress-buffering hypothesis.

Hypothesis four, which investigated whether campus connectedness moderated the relationship between perceived stress and anxiety, was not supported. It was predicted that campus connectedness would buffer the relationship between perceived stress and anxiety. The interaction of campus connectedness and perceived stress in predicting anxiety was non-significant. To date no additional research has been conducted investigating the role of campus connectedness in moderating the relationship between perceived stress and anxiety. These findings demonstrate campus connectedness does not interact with perceived stress to provide a protective effect on anxiety. Although previous research supports associations among these variables, the results of the current study did not support a buffering model and only demonstrate support for a main effect model of campus connectedness on anxiety [29]. The findings from the current study suggest campus connectedness appears to make a beneficial contribution in reducing anxiety regardless of perceived stress levels. Although only one of the current study's four moderation analyses was significant, the results of the analysis demonstrating campus connectedness buffers the relationship between perceived stress and depression are noteworthy. The results make a valuable contribution to the body of knowledge and increase our understanding of the potential protective role of campus connectedness in preventing university students with high levels of perceived stress from the development of depression.

A number of limitations are noted with the current study. Firstly, the study did not control for social desirability biases and it is possible this may have influenced participants' responses. Future studies should consider the inclusion of a social desirability scale to avoid potential confounding of results. Another limitation of the current study was that a general measure of perceived stress was used and therefore it may not have fully encapsulated the unique stressors university students encounter. Future studies could use a measure of perceived stress that specifically assesses the stressors university students' experience. As the current study is the first to date to investigate the moderating role of campus connectedness, it is suggested future research is conducted to gain a further understanding of its protective utility in buffering the relationship between perceived stress, and depression. In addition, the moderating effects of variables such as resilience or optimism could be investigated to determine whether they can be fostered as protective factors in the university context.

The results from this study offer a valuable contribution to the literature in furthering our understanding of the utility of psychosocial factors in protecting university students on an international level from the adverse consequences of high levels of perceived stress, including the development of anxiety and depression. Cohen and Wills' [22] stress-buffering hypothesis was not supported within the current sample, suggesting that less emphasis should be placed on the protective role of perceived social support on perceived stress, anxiety, and depression among university students. However, the results from the current study provide support for both a main effect and buffering model of campus connectedness. Therefore, increasing campus connectedness in university students will result in deceases in levels of both depression and anxiety. Furthermore, recognising that psychosocial factors such as campus connectedness may protect university students from the development of stressinduced depression adds to the emerging body of literature surrounding connectedness within the university context. To reduce the high prevalence rates of mental health problems in university students, it seems likely that facilitating campus connectedness would provide positive outcomes for the mental health of university students. Future research should be directed towards examining the effectiveness of preventative programs and in- 
terventions that promote campus connectedness. Universities should remain committed to promoting campus connectedness in university students through the development of programs and activities that promote student diversity, cultural unity, and belonging, such as interest groups [30].

The present study has important implications for higher education, as findings indicate that university students who are more connected have lower levels of perceived stress, anxiety, and depression. These findings demonstrate it is important for students to become involved in and feel a part of their university communities in order to be protected against the effects of stress and, consequently, the occurrence of psychological distress. With the knowledge that campus connectedness buffers the relationship between perceived stress and depression, university students with higher levels of campus connectedness may be protected from the adverse effects of stress and the development of depression. The current study has provided insight into the benefits of increasing campus connectedness in university students internationally to promote psychological wellbeing and adjustment. This awareness should be used to initiate programs for universities in Australia, Hong Kong, and the United States to reduce the prevalence rates of mental health problems in university students.

\section{References}

[1] Lee, C., Dickson, D.A., Conley, C.S. and Holmbeck, G.N. (2014) A Closer Look at Self-Esteem, Perceived Social Support, and Coping Strategy: A Prospective Study of Depressive Symptomatology across the Transition to College. Journal of Social and Clinical Psychology, 33, 560-585. http://dx.doi.org/10.1521/jscp.2014.33.6.560

[2] Bewick, B., Koutsopoulou, G., Miles, J., Slaa, E. and Barkham, M. (2010) Changes in Undergraduate Students’ Psychological Wellbeing as They Progress through University. Studies in Higher Education, 35, 633-645. http://dx.doi.org/10.1080/03075070903216643

[3] Andrews, B. and Wilding, J.M. (2004) The Relation of Depression and Anxiety to Life-Stress and Achievement in Students. British Journal of Psychology, 95, 509-521. http://dx.doi.org/10.1348/0007126042369802

[4] Chen, L., Wang, L., Qiu, X.H., Yang, X.X., Qiao, Z.X., Yang, Y.J. and Liang, Y. (2013) Depression among Chinese University Students: Prevalence and Socio-Demographic Correlates. PLoS One, 8, 667-672. http://dx.doi.org/10.1007/s00127-008-0345-X

[5] Wintre, M.G. and Yaffe, M. (2000) First-Year Students’ Adjustment to University Life as a Function of Relationships with Parents. Journal of Adolescent Research, 15, 9-37. http://search.proquest.com/docview/211625077?accountid=26503 http://dx.doi.org/10.1177/0743558400151002

[6] Vaez, M., Kristenson, M. and Laflamme, L. (2004) Perceived Quality of Life and Self-Rated Health among First-Year University Students. Social Indicators Research, 68, 221-234. http://dx.doi.org/10.1023/B:SOCI.0000025594.76886.56

[7] Gruttadaro, D. and Crudo, D. (2012) College Students Speak: A Survey on Mental Health. National Alliance on Mental Health. www.nami.org/namioncampus

[8] Cohen, S. (2004) Social Relationships and Health. The American Psychologist, 59, 676-684. http://dx.doi.org/10.1037/0003-066X.59.8.676

[9] Dahlem, W.N., Zimet, D.G. and Walker, R.R. (1991) The Multidimensional Scale of Perceived Social Support: A Confirmation Study. Journal of Clinical Psychology, 47, 756-761.

[10] El Ansari, W., Stock, C., Snelgrove, S., Hu, X., Parke, S., Davies, S. and Mabhala, A. (2011) Feeling Healthy: A Survey of Physical and Psychological Wellbeing of Students from Seven Universities in the UK. International Journal of Environmental Research and Public Health, 8, 1308-23. http://dx.doi.org/10.3390/ijerph8051308

[11] Lee, R.M., Dean, B.L. and Jung, K.R. (2008) Social Connectedness, Extraversion, and Subjective Wellbeing: Testing a Mediation Model. Personality and Individual Differences, 45, 414-419. http://dx.doi.org/10.1016/j.paid.2008.05.017

[12] Eisenbarth, C.A., Champeau, D.A. and Donatelle, R.J. (2013) Relationship of Appraised Stress, Coping Strategies, and Negative Affect among College Students. International Journal of Psychology and Behavioral Sciences, 3, 131-138.

[13] Hammen, C., Brennan, P.A. and Shih, J.H. (2004) Family Discord and Stress Predictors of Depression and Other Disorders in Adolescent Children of Depressed and Nondepressed Women. Journal of the American Academy of Child \& Adolescent Psychiatry, 43, 994-1002. http://dx.doi.org/10.1097/01.chi.0000127588.57468.f6

[14] Stewart-Brown, S., Evans, J., Patterson, J., Petersen, S., Doll, H., Balding, J. and Regis, D. (2000) The Health of Students in Institutes of Higher Education: An Important and Neglected Public Health Problem. Journal of Public Health Medicine, 22, 492. http://dx.doi.org/10.1093/pubmed/22.4.492

[15] Stallman, H.M. (2010) Psychological Distress in University Students: A Comparison with General Population Data. Australian Psychologist, 45, 249-257.

[16] Eisenberg, D., Speer, N. and Hunt, J.B. (2012) Attitudes and Beliefs about Treatment among College Students with 
Untreated Mental Health Problems. Psychiatric Services, 63, 711-713. http://dx.doi.org/10.1037/0002-9432.77.4.534

[17] Wong, J.G.W.S., Cheung, E.P.T., Chan, K.K.C., Ma, K.K.M. and Tang, S.W. (2006) Web-Based Survey of Depression, Anxiety and Stress in First-Year Tertiary Education Students in Hong Kong. The Australian and New Zealand Journal of Psychiatry, 40, 777-782. http://dx.doi.org/10.1111/j.1440-1614.2006.01883.x

[18] Uchino, B.N. (2009) Understanding the Links between Social Support and Physical Health: A Life-Span Perspective with Emphasis on the Separability of Perceived and Received Support. Perspectives on Psychological Science, 4, 236255. http://dx.doi.org/10.1111/j.1745-6924.2009.01122.x

[19] Hyde, L.W., Gorka, A., Manuck, S.B. and Hariri, A.R. (2011) Perceived Social Support Moderates the Link between Threat-Related Amygdala Reactivity and Trait Anxiety. Neuropsychologia, 49, 651-656. http://dx.doi.org/10.1016/j.neuropsychologia.2010.08.025

[20] Thoits, P.A. (2011) Mechanisms Linking Social Ties and Support to Physical and Mental Health. Journal of Health and Social Behaviour, 52, 145-161. http://dx.doi.org/10.1177/0022146510395592

[21] Warner, R.M. (2013) Applied Statistics: From Bivariate through Multivariate Techniques. SAGE Publications, Thousand Oaks.

[22] Cohen, S. and Wills, T.A. (1985) Stress, Social Support, and the Buffering Hypothesis. Psychological Bulletin, 98, $310-357$. http://dx.doi.org/10.1037/0033-2909.98.2.310

[23] Lazarus, S.R. and Folkman, S. (1984) Stress, Appraisal, and Coping. Springer Publishing Company, New York.

[24] Skok, A., Harvey, D. and Reddihough, D. (2006) Perceived Stress, Perceived Social Support, and Wellbeing among Mothers of School-Aged Children with Cerebral Palsy. Journal of Intellectual and Developmental Disability, 31, 53-57. http://dx.doi.org/10.1080/13668250600561929

[25] Chao, R.C.L. (2012) Managing Perceived Stress among College Students: The Roles of Social Support and Dysfunctional Coping. Journal of College Counseling, 15, 5-21. http://dx.doi.org/10.1002/j.2161-1882.2012.00002.x

[26] Yarcheski, A. and Mahon, N.E. (1999) The Moderator-Mediator Role of Social Support in Early Adolescents. Western Journal of Nursing Research, 21, 685-698. http://dx.doi.org/10.1177/01939459922044126

[27] Williams, K.L. and Galliber, R.V. (2006) Predicting Depression and Self-Esteem from Social Connectedness, Support, and Competence. Journal of Social and Clinical Psychology, 25, 855-874. http://dx.doi.org/10.1521/jscp.2006.25.8.855

[28] Lee, R.M. and Robbins, S.B. (1995) Measuring Belongingness: The Social Connectedness and the Social Assurance Scales. Journal of Counselling Psychology, 42, 232. http://dx.doi.org/10.1037/0022-0167.45.3.338

[29] Leary, K.A. and DeRosier, M.E. (2012) Factors Promoting Positive Adaptation and Resilience during the Transition to College. Psychology, 3, 1215-1222. http://dx.doi.org/10.4236/psych.2012.312A180

[30] Lee, R.M., Keough, K.A. and Sexton, J.D. (2002) Social Connectedness, Social Appraisal, and Perceived Life Stress in College Women and Men. Journal of Counselling and Development, 80, 355-361. http://dx.doi.org/10.1002/j.1556-6678.2002.tb00200.x

[31] Townsend, K.C. and McWhirter, B.T. (2005) Connectedness: A Review of the Literature with Implications for Counseling, Assessment, and Research. Journal of Counseling and Development, 83, 191-201. http://dx.doi.org/10.1002/j.1556-6678.2005.tb00596.x

[32] Rude, S.S. and Burnham, B.L. (1995) Connectedness and Neediness: Factors of the DEQ and SAS Dependency Scales. Cognitive Therapy and Research, 19, 323-340. http://dx.doi.org/10.1007/BF02230403

[33] Cohen, S., Kamarck, T. and Mermelstein, R. (1983) A Global Measure of Perceived Stress. Journal of Health and Social Behaviour, 24, 385-396. http://dx.doi.org/10.2307/2136404

[34] Lovibond, S.H. and Lovibond, P.F. (1995) Manual for the Depression Anxiety Stress Scales. 2nd Edition, Psychology Foundation, Sydney.

[35] Chaplin, W.F. (1991) The Next Generation of Moderator Research in Personality Psychology. Journal of Personality, 59, 143-178. http://dx.doi.org/10.1111/j.1467-6494.1991.tb00772.x

[36] Evans, M.G. (1985) A Monte Carlo Study of the Effects of Correlated Method Variance in Moderated Multiple Regression Analysis. Organisational Behaviour and Human Decision Processes, 36, 305-323. http://dx.doi.org/10.1016/0749-5978(85)90002-0

[37] Aiken, L.S. and West, S.G. (1991) Multiple Regression: Testing and Interpreting Interactions. Sage Publications, Inc., Thousand Oaks.

[38] Dawson, J.F. and Ritchter, A.Q. (2006) Probing Three-Way Interaction in Moderated Multiple Regression: Development and Application of a Slope Difference Test. Journal of Applied Psychology, 91, 917-926. http://dx.doi.org/10.1037/0021-9010.91.4.917 